\title{
Structural Characterisation and Mechanical FE Analysis of Conventional and M-Wire Ni-Ti Alloys Used in Endodontic Rotary Instruments
}

\author{
Diogo Montalvão, ${ }^{1}$ Francisca Sena Alçada, ${ }^{2}$ \\ Francisco Manuel Braz Fernandes, ${ }^{3}$ and Sancho de Vilaverde-Correia ${ }^{3,4}$ \\ ${ }^{1}$ School of Engineering and Technology, University of Hertfordshire, College Lane, Hatfield, Hertfordshire AL10 9AB, UK \\ ${ }^{2}$ The Dental Implant and Gingival-Plastic Surgery Centre, 717 Christchurch Road, Bournemouth, Dorset BH7 6AF, UK \\ ${ }^{3}$ CENIMAT/I3N, Materials Science Department, Faculty of Science and Technology, New University of Lisbon, \\ Campus of Caparica, 2829-516 Caparica, Portugal \\ ${ }^{4}$ Department of Endodontics, School of Dental Medicine, University of Pennsylvania, 3451 Walnut Street, Philadelphia, \\ PA 19104, USA
}

Correspondence should be addressed to Diogo Montalvão; d.montalvao@herts.ac.uk

Received 22 August 2013; Accepted 27 October 2013; Published 20 January 2014

Academic Editors: F. Cleymand, E. Sahmetlioglu, and S. Wu

Copyright (C) 2014 Diogo Montalvão et al. This is an open access article distributed under the Creative Commons Attribution License, which permits unrestricted use, distribution, and reproduction in any medium, provided the original work is properly cited.

\begin{abstract}
The purpose of this study is to understand how the M-Wire alloy conditions the mechanical flexibility of endodontic rotary files at body temperature.Two different rotary instruments, a Profile GT 20/.06 and a Profile GT Series X 20/.06, were selected due to their geometrical similarity and their different constituent alloy. GT series X files are made from M-Wire, a Ni-Ti alloy allegedly having higher flexibility at body temperature. Both files were analysed by X-Ray Diffraction and Differential Scanning Calorimetry to investigate phase transformations and the effects of working temperature on these different alloys. Mechanical behaviour was assessed by means of static bending and torsional Finite Element simulations, taking into account the nonlinear superelastic behaviour of Ni-Ti materials. It was found that GT files present austenitic phase at body temperature, whereas GT series X present $\mathrm{R}$-phase at temperatures under $40^{\circ} \mathrm{C}$ with a potential for larger flexibility. For the same load conditions, simulations showed that the slight geometrical differences between the two files do not introduce great disagreement in the instruments' mechanical response. It was confirmed that M-Wire increases the instrument's flexibility, mainly due to the presence of R-phase at body temperature.
\end{abstract}

\section{Introduction}

Stainless steel instruments are rigid and therefore unsuited for large apical enlargement in thin curved canals [1]. $\mathrm{Ni}-\mathrm{Ti}$ alloys have superior properties in ductility, fatigue, recoverable strain, biocompatibility, and corrosion resistance [2]. Ni-Ti alloys' lower Young's modulus and superelastic behaviour are paramount for preparation of anatomically complex root canals, as flexibility preserves dental structure, limits apical transport, reduces the risk of iatrogenic mistakes, and ultimately allows for irrigants to flow deeper in canals, towards the apical constriction $[3,4]$. Also, some studies claim that there is now evidence [5] that Ni-Ti instruments yield better clinical prognosis in endodontics when compared to their stainless steel counterparts considered alone.

However, Ni-Ti files present a higher risk of unnoticed fracture inside canals [6], contrary to stainless steel files that often present visible signs of plastic deformation [7]. Unexpected premature file fracture is of paramount concern as it might hinder clinical outcome. Some published studies show that $\mathrm{Ni}-\mathrm{Ti}$ instruments fracture at a frequency ten times greater than their stainless steel counterparts $[8,9]$. Furthermore, Ni-Ti fragments are up to seven times less likely to be removed from inside root canals, even by experienced endodontists [10]. This explains the current interest in the subject by several researchers [11-17]. 
Recent fabrication of superelastic files is mostly focused on geometrical details, with emphasis on cross-sectional design [18-21]. Alongside, there have been significant developments in material properties. Endodontic files $\mathrm{Ni}-\mathrm{Ti}$ should ideally have excellent mechanical strength properties (measured by both the ultimate tensile strength and the fatigue strength), it should be flexible enough to avoid canal transportation, and its hardness should be large enough to allow for good cutting efficacy [22, 23].

Flexibility in Ni-Ti files due to their superelastic behaviour mainly depends on the crystallographic phases present in the alloy and the thermal, mechanical, and chemical treatments to which the alloy has been subjected. Ni-Ti alloys used in root canal treatment contain approximately 55\%(wt) $\mathrm{Ni}$ and $45 \%$ (wt) $\mathrm{Ti}$ [22], equivalent to 50\%(at) $\mathrm{Ni}$ and 50\%(at) Ti.

Shape Memory Effect (SME) and Superelasticity (SE) are associated with the reversible nature of the martensitic transformation that happens in Shape Memory Alloys (SMA). This transformation may be thermally and/or mechanically induced. In the absence of applied stress, there are two temperatures, Ms and Mf, corresponding to the beginning and end of austenite (A) to martensite (M) transformation during cooling (direct transformation), and other two temperatures, As and Af, corresponding to the beginning and end of $\mathrm{M}$ to A transformation during heating (reverse transformation). Deformation of the thermally stable austenite (above Af) will lead to formation of stress induced martensite (SIM) above a critical stress that is temperature dependent. Due to crystallographic reversibility of this SIM transformation, the resulting strain (up to $10 \%$ in $\mathrm{Ni}$-Ti alloys) may be completely recovered, which accounts for the superelastic effect. Such recoverable strain is much higher than the maximum elastic strain (up to $0.2 \%$ ) that can be recovered in steels, namely, the stainless steel used in manual endodontic files. The A$\mathrm{M}$ transformation may occur in one single step. However, according to the processing conditions [24-26], this A-M transformation may also go through an intermediate step [27, 28] (R-phase, first identified by Nagasawa in 1970 and later reported as a rhombohedral distortion of the parent A phase). R-phase has a much smaller stiffness than the other two phases, thus allowing for stress relaxation during deformation of endodontic instruments inside root canals; this means that the loads needed to deform files, either in bending or in torsion, are also much smaller. This characteristic, along with the very low thermal hysteresis of A-R-phase transformation (just a few degrees, compared to several tens of degrees for A-M), explains the great importance of determining the temperature range for R-phase existence in these endodontic files.

The crystallographic structure of superelastic Ni-Ti instruments' alloy at room temperature under no-load is austenite. Martensite in Ni-Ti alloys can be stress induced by a shear type of process, as it happens when rotary files are deformed by root canals' anatomical curvatures. Since austenite is the stable phase at this temperature, the material springs back to its original shape when stress is removed. Recent developments have improved the properties of rotary instrument files by using new alloys with special thermal treatments and new manufacturing processes [29]. The newly introduced to the market M-Wire is an example of such a $\mathrm{Ni}$-Ti alloy nowadays seen in many files. According to its manufacturer, this alloy is thermomechanically processed in order to have a larger flexibility at body temperature than conventional Ni-Ti wire [30].

As Ni-Ti alloy properties depend on the materials' crystallographic phase, the present study will firstly characterize the material from two file types with geometrical similarities but different alloys: Profile GT 20/.06 (GT) and Profile GT Series X 20/.06 (GTX) files. Characterization will be carried out through X-Ray Diffraction (XRD) and Differential Scanning Calorimetry (DSC) as these are important methods to identify which phases are present and their evolution as a function of temperature $[31,32]$. Secondly, some flexural and torsional simulations will be performed using Finite Element (FE) models, under the same loads and boundary conditions as those used by other authors [18-20].

The ultimate purpose is to investigate the presence of Rphase in M-Wire at body temperature and to understand how its presence interacts with endodontic file deformation and internal stresses relaxation. This is an all-encompassing study, following a smaller previous analysis [12], adding fundamental missing information regarding body temperature, which is a paramount parameter for NiTi instruments performance under clinical use.

\section{Materials and Methods}

2.1. Geometrical Considerations. Two as-received Ni-Ti rotary files with similar cross-sections-but different material properties-were selected for this study (Figure 1): Profile GT 20/.06 (GT) is made from conventional Ni-Ti alloy and GT series X 20/.06 (GTX) is made from M-Wire (both files were provided by Dentsply Tulsa Dental Specialties, Tulsa, OK). A Mitutoyo PJ-A300 with QM Data 200 profile projector, a Leica Zoom 2000 microscope, and a OPTIKA microscope with numeric ocular camera JEULIN 571205 were used to assist in the geometrical characterization of both GT and GTX files.

The purpose is that the CAD (Computer Assisted Design) geometrical models used in the FE analysis resemble the real files as much as possible, including variable radial land widths along the instruments' active parts. Usually, the file can be divided into three main parts: handle, shaft, and blade. The total length of both files compared in this study is $17 \mathrm{~mm}$ with a $14.3 \mathrm{~mm}$ long working part. In addition, both instruments have a $1 \mathrm{~mm}$ diameter at the transition section between the shaft and blade and approximately $6 \%$ taper. However, there are some differences between the GT and GTX files, which are shown in Figure 1. Compared with the GT file, the GTX has fewer spirals because of its larger pitch length. Besides, the pitch lengths of both the GT and GTX files are variable. Furthermore, the radial land widths on the GTX files are deeper than in the GT file, because of the narrower angled cutting edges. The CAD models, shown in Figure 1, accurately reproduce the actual dimensions of the working part of the instruments, which can be seen from the superposition of the 


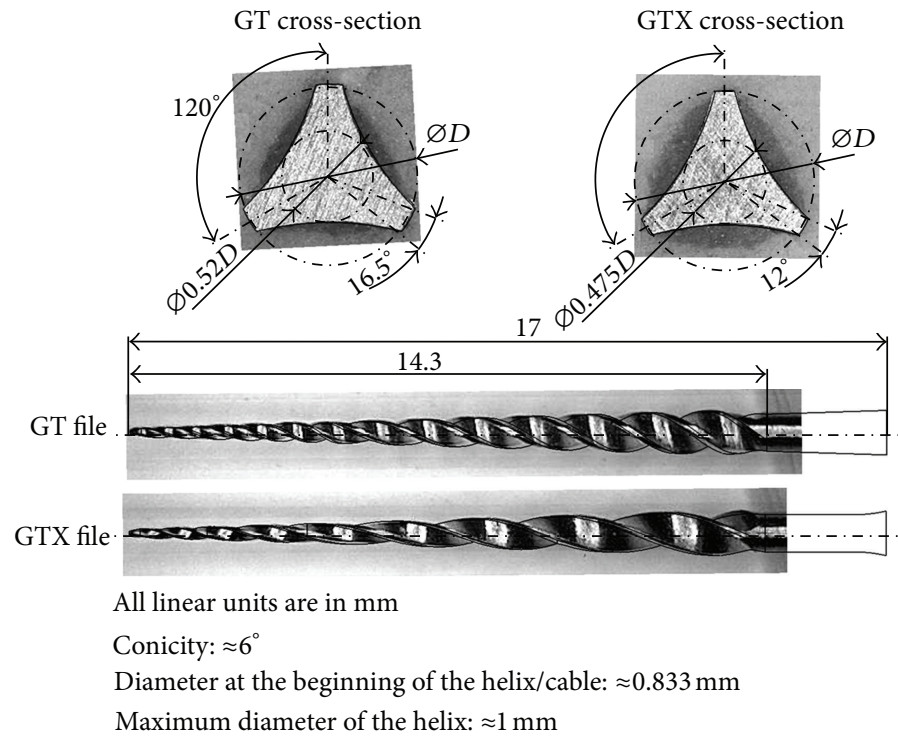

FIGURE 1: Cross-sectional and longitudinal geometries of the GT and GTX file instruments used in this study, where $D$ stands for the local diameter.

models' edges over the photos, including different triple Ushaped cross-sections and variable land widths.

2.2. X-Ray Diffraction Tests. Six shafts of each file type-GT and GTX-were embedded in epoxy resin (Epo-Thin, Buehler, Germany) cylinder blocks and after cure they were slightly abraded with number 350 Silicon Carbide Waterproof Paper (Struers, Denmark). Shafts were then removed from their resin cast, their new flat surface was glued to a small piece of glass and flipped over before being included in a new epoxy resin cylinder. After cure, the metal was again abraded with sand paper until the shafts' maximum diameters were reached in order to obtain an area for analysis as large as possible. Samples were then removed from within the resin and mounted with silver colloid glue on the sample holder of the TTK-450 chamber, mounted on the XRD.

XRD measurements were performed using a diffractometer with a Bragg-Brentano mounting employing $\mathrm{Cu}$ $\mathrm{K} \alpha$ radiation (wavelength of $1.54 \AA$ ) produced by a rotating anode. The scanning was set up and programmed in the following way:

(i) test samples were analysed over a $2 \theta$ range from $30^{\circ}$ to $55^{\circ}$, using an increment step size of $0.04^{\circ}$, with a counting time of 0.5 seconds at each step;

(ii) angular scans were run for each file between temperatures of $T$ (minimum) $=-180^{\circ} \mathrm{C}$ and $T(\max )=100^{\circ} \mathrm{C}$ (cooling and heating).

2.3. DSC Analysis. Transformation temperatures of $\mathrm{A} \Leftrightarrow \mathrm{R}$ phases were determined by DSC. A shaft of each file was cut into five fragments, weighted, and analysed in a Setaram DSC92 calorimeter in the temperature range of $-40^{\circ} \mathrm{C}$ to $100^{\circ} \mathrm{C}$, with heating and cooling at $7.5^{\circ} \mathrm{C} / \mathrm{min}$.
2.4. Finite Element Modelling. GT and GTX files were modelled using Solidworks (three-dimensional computeraided design software) and ANSYS 14.0 (computer-aided engineering software). Both geometries try to fit the real files as much as possible, with larger pitch length and variable radial land widths along the GTX instrument's active part. The geometrical model used in this section is improved in comparison to the one used in a previous simulation [12]: the concave (U-shaped flutes) cross-sections were actually assessed by cutting the files transversely as shown in Figure 1 and explained in Section 2.1 earlier. It may be seen that there are some differences between the GT and GTX crosssections. This way, it is possible to also study the effects of the different geometries in the files' flexibility.

Tetrahedral structural solid elements (SOLID187), suited for complex geometries and for modelling irregular meshes [33], were used in the FE models. Meshes for the GT and GTX files consisted of 8681 nodes, 4441 elements and 4700 elements, 9119 nodes, respectively, with both being applied using mapped face meshing. The GTX file mesh is illustrated in Figure 2. The multikinematic hardening plastic material model was selected in the software to approximate the stressstrain relationships of the $\mathrm{Ni}-\mathrm{Ti}$ alloys used in dentistry [18$20,34]$. For the general mechanical properties, a linear elastic isotropic material model was selected. The combination of both models for the material characterization was done following other works [18]. The files' material properties were modelled by considering the stress-strain relationships for conventional Ni-Ti and M-Wire found in the literature [34].

Two comparisons have been established between the GT and the GTX endodontic rotary files:

(1) geometrical comparison: in this comparison both files were modelled considering the same material properties (conventional Ni-Ti), to evaluate the effect of the geometry alone on the instrument's performance; 
FE mesh and simulated conditions (example for a GTX file):

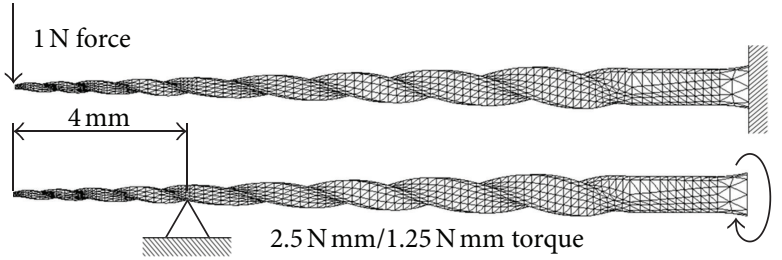

FIGURE 2: Finite Element model mesh with load and boundary conditions (example for a GTX file).

(2) material comparison: in this comparison the files were modelled using different stress-strain material models [35]; the Poisson's coefficient was considered 0.33 for both alloys [36].

The mechanical behaviour of the files was analysed by using similar loading and boundary conditions as in other works [18-20] (Figure 2):

(1) evaluation of the equivalent (von Mises) stress distribution and tip deflection in bending: the instrument was clamped at the shaft's cable and subjected to a load of $1 \mathrm{~N}$ at its tip;

(2) evaluation of the equivalent (von Mises) stress distribution and shaft rotation in torsion: the instrument was clamped $4 \mathrm{~mm}$ away from its tip and two different torques of $2.5 \mathrm{Nmm}$ and $1.25 \mathrm{Nmm}$ were applied at the edge of the shaft's cable, one at a time.

\section{Results}

3.1. X-Ray Diffraction Results. A series of XRD scans, corresponding to different temperatures, were obtained during the cooling and heating cycles of both GT and GTX files' fragments. Only the patterns obtained during cooling are shown in Figure 3. International Crystallographic Diffraction Data (ICDD) cards were used to identify diffraction peaks of austenite-B2(110) -, R-phase-R(102), R(112), R(300), and $\mathrm{R}(202)$ - and martensite-B19'.

In Figure 3 the diffraction peaks of both files are shown at five representative temperatures: $80,40,20,-40$, and $-180^{\circ} \mathrm{C}$. At $80^{\circ} \mathrm{C}$, both files are fully austenitic and at $-180^{\circ} \mathrm{C}$ both are almost fully martensitic. R-phase presence appears as a broadening of the B2(110) because of the splitting of this peak into the two neighbouring R-phase diffraction peaks: $\mathrm{R}(112)$ and $\mathrm{R}(300)$.

A more detailed analysis of these results shows that:

(i) the austenite B2(110) peak's intensity decreases from $40^{\circ} \mathrm{C}$ downwards with a corresponding slight increase of the R-phase peaks' intensity for the GTX file while for the GT file this is more noticeable only below $20^{\circ} \mathrm{C}$;

(ii) R-phase peaks' intensity increases significantly during cooling, until $-40^{\circ} \mathrm{C}$ is reached, in both files;

(iii) martensite peaks' intensity increases more significantly for temperatures below $-40^{\circ} \mathrm{C}$, for both files;

(iv) $\mathrm{Ni}_{4} \mathrm{Ti}_{3}$ precipitates are present in both files.
3.2. DSC Results. Transformation temperatures were determined by DSC (Figure 4). The transformation temperatures of the GTX files are clearly shifted towards a higher temperature range and this result is consistent with the observations from XRD. Also from the XRD results we can say that, for the thermal cycle run between $80^{\circ} \mathrm{C}$ and $-40^{\circ} \mathrm{C}$, mostly the austenite $\Leftrightarrow \mathrm{R}$-phase transformation was identified during DSC tests. In both files, from close to room temperature $\left(20^{\circ} \mathrm{C}\right)$ up to sterilization temperature only the austenite $\Leftrightarrow$ R-phase transformation will be taking place and at a temperature close to body temperature $\left(37^{\circ} \mathrm{C}\right) \mathrm{GT}$ file will be fully austenitic, while GTX file will be austenite + R-phase.

3.3. Finite Element Results. Some representative results of the von Mises distribution along the files are shown on Figure 5. The stress versus load relationships in both bending and torsion are shown on Figure 6. Table 1 summarizes the whole results.

\section{Discussion}

4.1. X-Ray Diffraction Analysis. There are differences between GT and GTX alloys, namely, different phases present at equal temperatures. The three Ni-Ti alloy phases can be identified through X-Ray Diffraction, although the temperature range used in this study $\left(T=\left[-40^{\circ} \mathrm{C} ; 100^{\circ} \mathrm{C}\right]\right)$ is not enough for identifying martensite, which occurs at lower temperatures.

The wide test temperature range was defined not only for encompassing clinically relevant temperatures (near $37^{\circ} \mathrm{C}$ ) and ambient temperature, but also because it is known [31] that there is a phase transformation between $T=-20^{\circ} \mathrm{C}$ and $T=80^{\circ} \mathrm{C}$. Although files are sterilized at temperatures higher than $100^{\circ} \mathrm{C}$, there is no need to reach such large values as austenite is known [31] to be the only phase present beyond $100^{\circ} \mathrm{C}$.

XRD (and DSC) data show that R-phase appears at higher temperatures for GTX file than for GT file. R-phase is present in GT file's alloy in the range of temperatures close to $10^{\circ} \mathrm{C}$ in the cooling cycle. On the other hand, GTX file's alloy has Rphase around $40^{\circ} \mathrm{C}$ both in cooling and heating cycles. This means that, at body temperature $\left(\approx 37^{\circ} \mathrm{C}\right)$, GT is austenitic and GTX already presents a significant amount of R-phase. R-phase allows for stress relaxation during adaptation of an endodontic file to root canal curvatures; thus, loads needed to deform it, either in bending or in torsion, are much smaller than those needed to deform austenitic instruments.

$\mathrm{R}$-phase is many times not taken into consideration when designing Ni-Ti alloys for endodontic rotary files, although this crystallographic phase brings important mechanical properties, such as a lower Young's modulus when compared to the austenitic phase. Consequently, its flexibility is larger so the internal stresses of the material inside a given curved root canal are smaller, which increases mechanical resistance under fatigue cyclic loading [29].

In conclusion, XRD analysis showed GTX files to have R-phase at body temperature $\left(37^{\circ} \mathrm{C}\right)$ and may, therefore, be better suited for instrumentation of curved canals than GT files (which are austenitic at body temperature). 


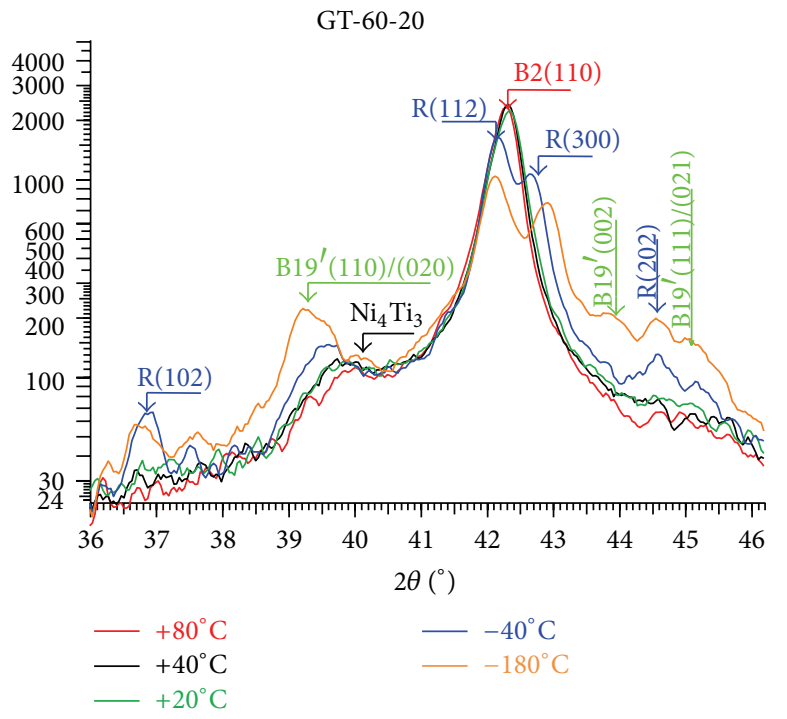

(a)

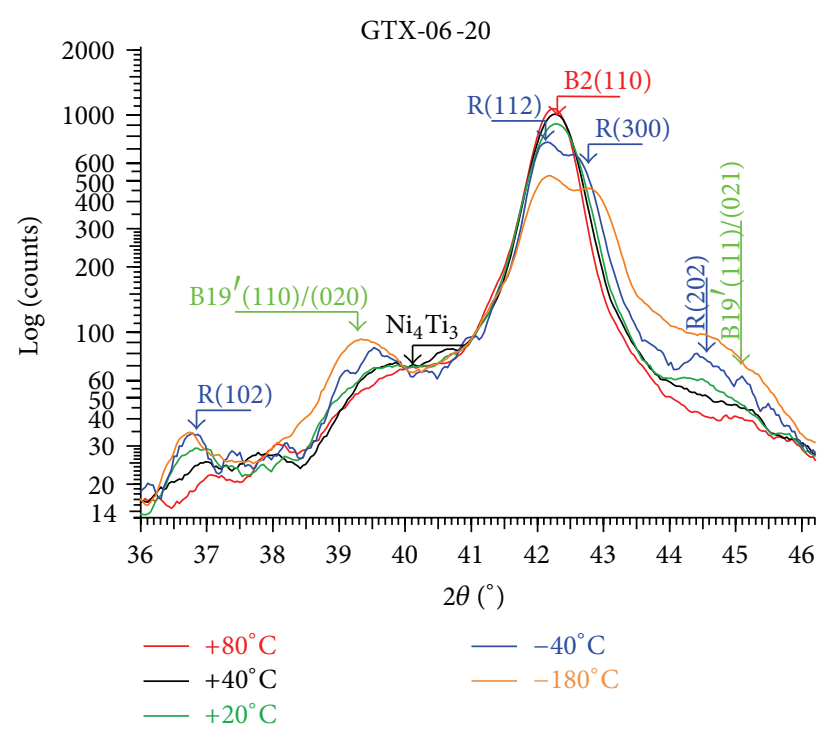

(b)

FIGURE 3: 3D XRD patterns during cooling of both GT and GTX files, with identification of the austenite (B2), R-phase, and martensite (B19') peaks: a selection of 5 scans at $+80,+40,+20,-40$, and $-180^{\circ} \mathrm{C}$, and a $3 \mathrm{D}$ view of this selected group of scans is shown.

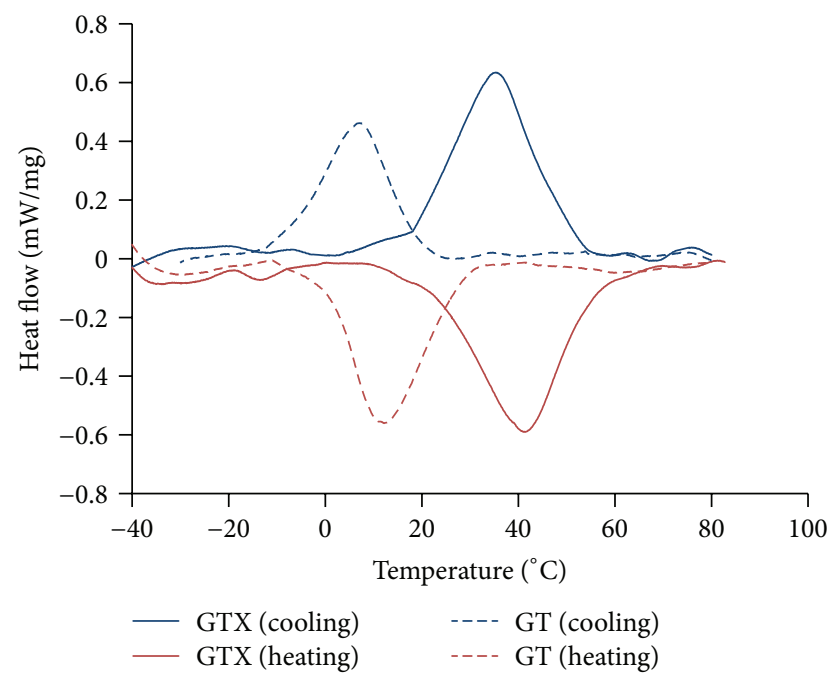

FIGURE 4: DSC curves for GT and GTX files obtained for cooling until $-40^{\circ} \mathrm{C}$.

4.2. DSC Analysis. The DSC curves show, during cooling, a clear shift of the transformation temperatures from peak temperature close to $35^{\circ} \mathrm{C}$ for GTX file to a peak temperature close to $5^{\circ} \mathrm{C}$ for GT file. A similar shift is also found, during heating. The trends of the curves for both files during cooling let us presume that cooling until $-40^{\circ} \mathrm{C}$ gives rise mostly to $\mathrm{A} \Leftrightarrow \mathrm{R}$ but also a minor amount of martensite may be formed. This analysis is consistent with the XRD data previously presented.

4.3. Finite Element Analysis: Geometrical Comparison. As far as a geometrical comparison is concerned, from Table 1 one may consider that the deformation differences between the GT and GTX geometries are residual in bending (4.4\% difference when the deflection is measured on the tip for a $1 \mathrm{~N}$ force). On the contrary, for the same torque and boundary conditions, the GTX geometry alone is already introducing flexibility with approximately twice the angular deformation of the GT file in both simulations.

It is important to notice that, as the files are subjected to a heterogeneous stress distribution (shown by the colour gradient visible from the central axis to the boundary, both in bending and in torsion), different phases are present throughout the file's cross-sections. That is why a stress relaxation occurs when a certain threshold is achieved (visible on the plateaus in Figure 6) that is due to the material phase transformations happening during the deformation. At these regions the deformation will increase with the load level, but the maximum stress in the material will not suffer a significant change.

4.4. Finite Element Analysis: Materials Comparison. A comparison between GT and GTX files was also made taking into account the material model differences. The less stiff MWire, with a lower phase transition stress level, considerably increased the flexibility of the GTX file. For the same bending force ( $1 \mathrm{~N}$ at the tip), the GTX file was $27 \%$ more flexible than its GT counterpart $(7.29 \mathrm{~mm}$ tip deflection against $5.98 \mathrm{~mm}$ ). Likewise, the maximum stress measured in GTX was 19\% smaller than the one measured in GT, which may correspond to an enhanced endurance of GTX instruments clinically, although this suggestion deserves further investigation by considering dynamic rotation inside root canals. Also, for the same torque, GTX was considerably more flexible than GT, with a twist practically three times as large. The M-Wire GTX files are showed to be considerably more flexible and capable 


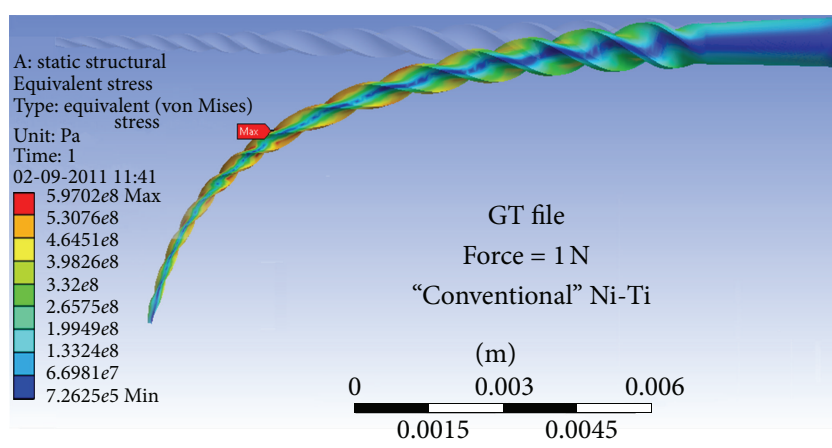

(a)

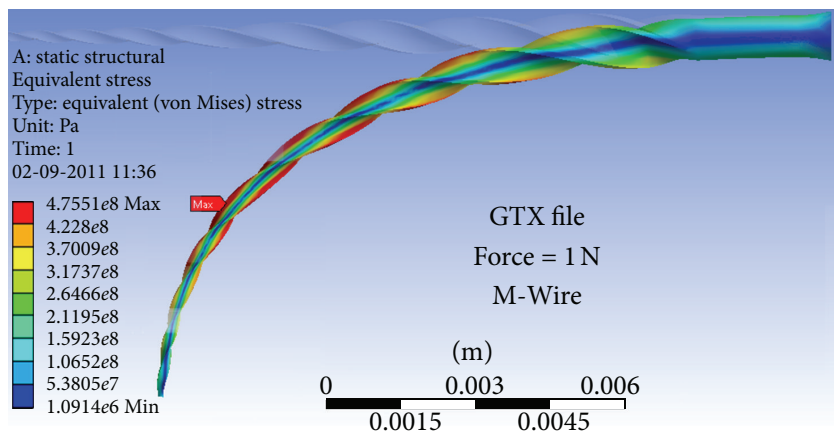

(c)

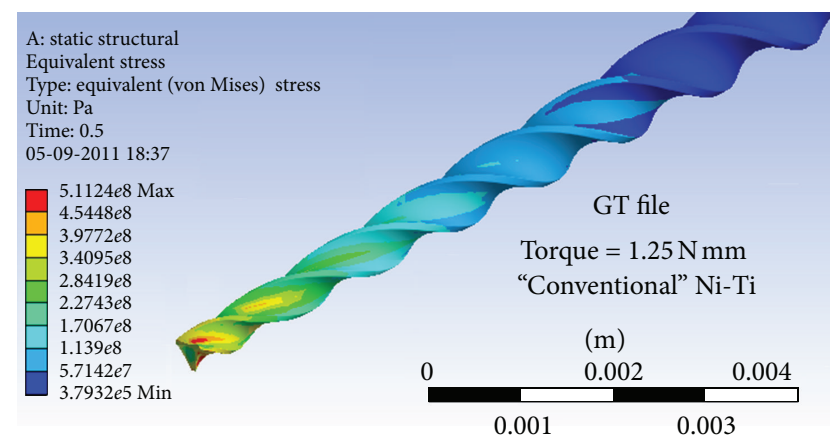

(b)

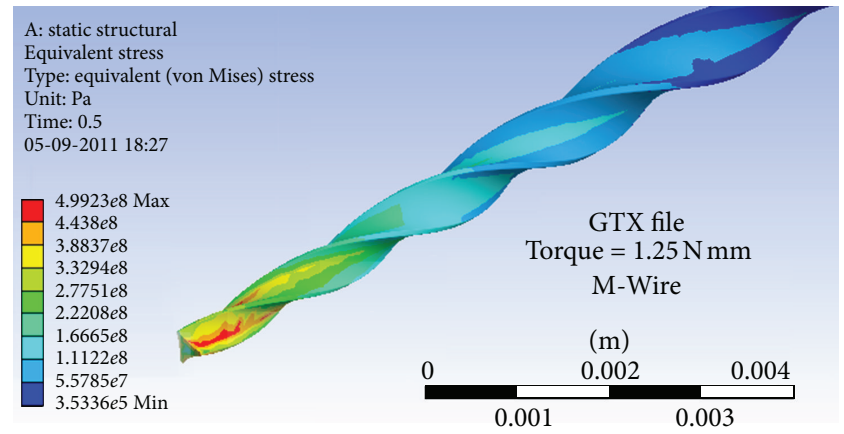

(d)

Figure 5: ((a), (c)) Flexural von Mises stress distribution for a $1 \mathrm{~N}$ load at the tip. ((b), (d)) Torsional von Mises stress distribution for a $1.25 \mathrm{Nmm}$ torque with the file clamped $4 \mathrm{~mm}$ away from its tip.

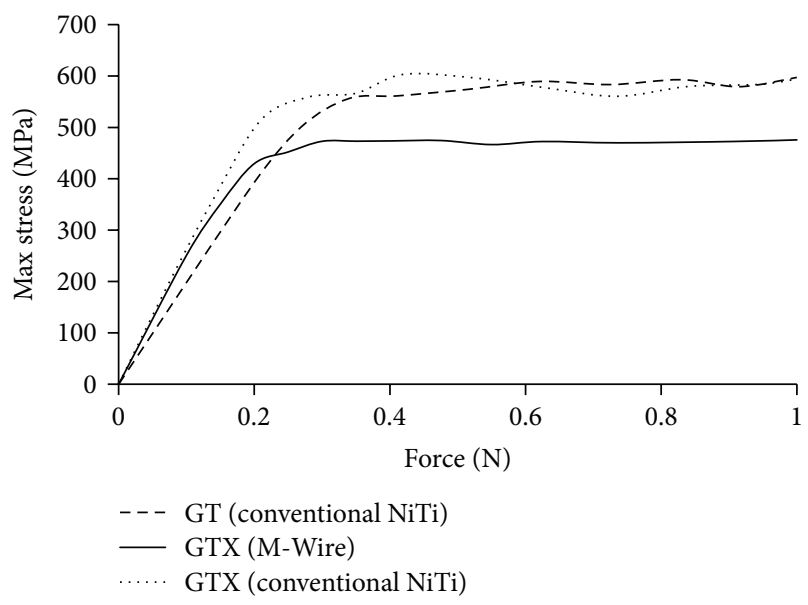

(a)

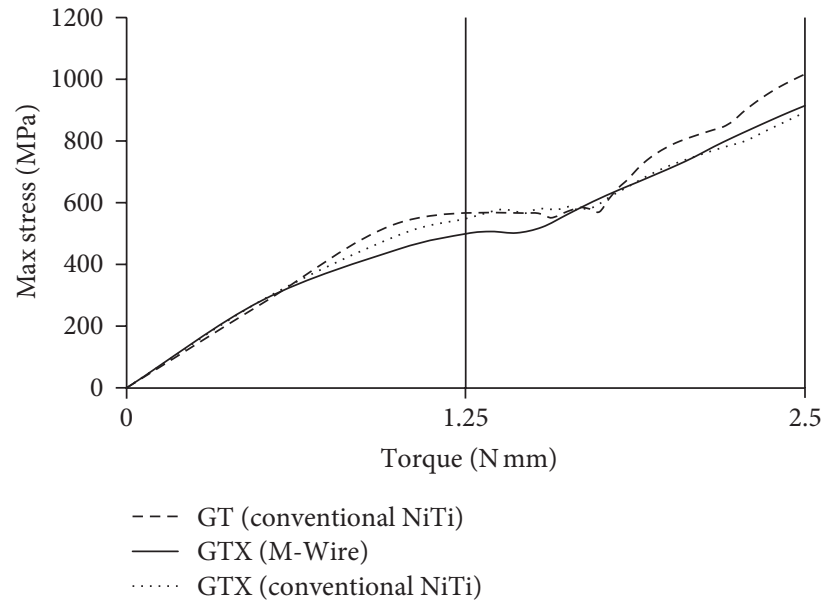

(b)

FIGURE 6: (a) Evolution of the maximum stress for bending simulation (up to $1 \mathrm{~N}$ ). (b) Evolution of the maximum stress for torsion simulation (up to $2.5 \mathrm{Nmm}$ ).

of stress relief at the most critical zones than GT instruments. Other than temperature effects, this increased flexibility is due to a smaller Young's modulus.

\section{Conclusions}

In conclusion, the relevant combination of $\mathrm{FE}$ results with results from DRX and DSC made it possible to conclude that there are flexibility related benefits in M-Wire files at body temperature $\left(37^{\circ} \mathrm{C}\right)$. Also, under conditions of the present study, it is suggested that this property might reflect positively on the dynamic rotation inside the root canals which is seen in the clinical situation.

Further study is still required to include the effects of cyclic loading in the performance of the endodontic rotary files. In that case, files should be modelled by using the SMA 
TABLE 1: Summary of the Finite Element modelling results (GT file's results were used as reference for the relative deformations and stresses).

\begin{tabular}{|c|c|c|c|c|c|c|}
\hline & Geometry & Material & $\begin{array}{c}\text { Absolute } \\
\text { deformation }\end{array}$ & $\begin{array}{c}\text { Relative } \\
\text { deformation }\end{array}$ & $\begin{array}{l}\text { Absolute maximum } \\
\text { stress }\end{array}$ & $\begin{array}{c}\text { Relative maximum } \\
\text { stress }\end{array}$ \\
\hline \multirow{3}{*}{ Force $1 \mathrm{~N}$} & GT & $\mathrm{NiTi}$ & $5.73 \mathrm{~mm}$ & - & $586 \mathrm{MPa}$ & - \\
\hline & \multirow{2}{*}{ GTX } & $\mathrm{NiTi}$ & $5.98 \mathrm{~mm}$ & $+4.4 \%$ & $594 \mathrm{MPa}$ & $+1.4 \%$ \\
\hline & & M-Wire & $7.29 \mathrm{~mm}$ & $+27.2 \%$ & $476 \mathrm{MPa}$ & $-18.8 \%$ \\
\hline \multirow{3}{*}{ Torque $2.5 \mathrm{~N} \mathrm{~mm}$} & GT & NiTi & $53^{\circ}$ & - & $1016 \mathrm{MPa}$ & - \\
\hline & \multirow{2}{*}{ GTX } & $\mathrm{NiTi}$ & $109^{\circ}$ & $+105.7 \%$ & $893 \mathrm{MPa}$ & $-12.1 \%$ \\
\hline & & M-Wire & $133^{\circ}$ & $+150.9 \%$ & $914 \mathrm{MPa}$ & $-10.0 \%$ \\
\hline \multirow{3}{*}{$1 / 2$ Torque $1.25 \mathrm{~N} \mathrm{~mm}$} & GT & $\mathrm{NiTi}$ & $13^{\circ}$ & - & $511 \mathrm{MPa}$ & - \\
\hline & \multirow{2}{*}{ GTX } & NiTi & $23^{\circ}$ & $+76.9 \%$ & $548 \mathrm{MPa}$ & $+7.2 \%$ \\
\hline & & M-Wire & $39^{\circ}$ & $+200.0 \%$ & $499 \mathrm{MPa}$ & $-2.3 \%$ \\
\hline
\end{tabular}

model instead, which includes hysteresis (different mechanical behaviour during loading and unloading). Nevertheless, extrapolation will still be needed, as this model does not envisage the accumulation of residual stresses or hardening.

\section{Conflict of Interests}

The authors declare that there is no conflict of interests regarding the publication of the paper.

\section{Acknowledgments}

The authors gratefully acknowledge financial support from FCT-Fundação para Ciência e Tecnologia (Project PTDC/EME-PME/122795/2010) and CENIMAT by PEstC/CTM/LA0025/2013-14 (Strategic Project-LA 25-20132014).

\section{References}

[1] E. Schäfer, "Relationship between design features of endodontic instruments and their properties. Part 2. Instrumentation of curved canals," Journal of Endodontics, vol. 25, no. 1, pp. 56-59, 1999.

[2] S. K. Wu, H. C. Lin, and P. C. Cheng, "Multi-strengthening effects on the martensitic transformation temperatures of TiNi shape memory alloys," Journal of Materials Science, vol. 34, no. 22, pp. 5669-5675, 1999.

[3] E. Schäfer and M. Oitzinger, "Cutting efficiency of five different types of rotary nickel titanium instruments," Journal of Endodontics, vol. 32, pp. 61-65, 2008.

[4] T. Kell, A. Azarpazhooh, O. A. Peters, O. El-Mowafy, B. Tompson, and B. Basrani, "Torsional profiles of new and used 20/.06 GT series X and GT rotary endodontic instruments," Journal of Endodontics, vol. 35, no. 9, pp. 1278-1281, 2009.

[5] M. T. Pettiette, E. Olutayo Delano, and M. Trope, "Evaluation of success rate of endodontic treatment performed by students with stainless-steel k-files and nickel-titanium hand files," Journal of Endodontics, vol. 27, no. 2, pp. 124-127, 2001.

[6] P. V. Patiño, B. M. Biedma, C. R. Liébana, G. Cantatore, and J. G. Bahillo, "The influence of a manual glide path on the separation rate of NiTi rotary instruments," Journal of Endodontics, vol. 31, no. 2, pp. 114-116, 2005.
[7] B. Martín, G. Zelada, P. Varela et al., "Factors influencing the fracture of nickel-titanium rotary instruments," International Endodontic Journal, vol. 36, no. 4, pp. 262-266, 2003.

[8] T. Sotokawa, "A systematic approach to preventing intracanal breakage of endodontic files," Endodontics \& Dental Traumatology, vol. 6, no. 2, pp. 60-62, 1990.

[9] B. Sattapan, G. J. Nervo, J. E. Palamara, and H. H. Messer, "Defects in rotary nickel-titanium files after clinical use," Journal of Endodontics, vol. 26, no. 3, pp. 161-165, 2000.

[10] P. Spili, P. Parashos, and H. H. Messer, "The impact of instrument fracture on outcome of endodontic treatment," Journal of Endodontics, vol. 31, no. 12, pp. 845-850, 2005.

[11] Y.-Z. Chang, M.-C. Liu, C.-A. Pai, C.-L. Lin, and K.-I. Yen, "Application of non-destructive impedance-based monitoring technique for cyclic fatigue evaluation of endodontic nickeltitanium rotary instruments," Medical Engineering and Physics, vol. 33, no. 5, pp. 604-609, 2011.

[12] D. Montalvão and F. S. Alçada, "Numeric comparison of the static mechanical behavior between profile GT and profile GT series X rotary nickel-titanium files," Journal of Endodontics, vol. 37, no. 8, pp. 1158-1161, 2011.

[13] C. G. Adorno, T. Yoshioka, and H. Suda, "Crack initiation on the apical root surface caused by three different nickel-titanium rotary files at different working lengths," Journal of Endodontics, vol. 37, no. 4, pp. 522-525, 2011.

[14] J.-Y. Kim, G. Shun-Pan Cheung, S.-H. Park, D.-C. Ko, J.-W. Kim, and H.-C. Kim, "Effect from cyclic fatigue of nickel-titanium rotary files on torsional resistance," Journal of Endodontics, vol. 38, no. 4, pp. 527-530, 2012.

[15] A. M. F. Leroy, M. G. A. Bahia, A. Ehrlacher, and V. T. L. Buono, "An analytical mechanical model to describe the response of NiTi rotary endodontic files in a curved root canal," Materials Science and Engineering C, vol. 32, pp. 1594-1600, 2012.

[16] E. Ninan and D. W. Berzins, "Torsion and bending properties of shape memory and superelastic nickel-titanium rotary instruments," Journal of Endodontics, vol. 39, pp. 101-104, 2013.

[17] H. Shahabinejad, A. Ghassemi, L. Pishbin, and A. Shahravan, "Success of ultrasonic technique in removing fractured rotary nickel-titanium endodontic instruments from root canals and its effect on the required force for root fracture," Journal of Endodontics, vol. 39, pp. 824-828, 2013.

[18] X. Xu, M. Eng, Y. Zheng, and D. Eng, "Comparative study of torsional and bending properties for six models of nickeltitanium root canal instruments with different cross-sections," Journal of Endodontics, vol. 32, no. 4, pp. 372-375, 2006. 
[19] T. O. Kim, G. S. P. Cheung, J. M. Lee, B. M. Kim, B. Hur, and H. C. Kim, "Stress distribution of three NiTi rotary files under bending and torsional conditions using a mathematic analysis," International Endodontic Journal, vol. 42, no. 1, pp. 14-21, 2009.

[20] H. C. Kim, H. J. Kim, C. J. Lee, B. M. Kim, J. K. Park, and A. Versluis, "Mechanical response of nickel-titanium instruments with different cross-sectional designs during shaping of simulated curved canals," International Endodontic Journal, vol. 42, no. 7, pp. 593-602, 2009.

[21] A. C. D. Viana, M. Chaves Craveiro de Melo, M. Guiomar de Azevedo Bahia, and V. T. Lopes Buono, "Relationship between flexibility and physical, chemical, and geometric characteristics of rotary nickel-titanium instruments," Oral Surgery, Oral Medicine, Oral Pathology, Oral Radiology and Endodontology, vol. 110, no. 4, pp. 527-533, 2010.

[22] S. A. Thompson, "An overview of nickel-titanium alloys used in dentistry," International Endodontic Journal, vol. 33, no. 4, pp. 297-310, 2000.

[23] J. Liu, S. Alapati, W. A. Brantley, W. Clark, and M. Iijima, "Vickers hardness study of clinically used M-Wire rotary endodontic instruments," Journal of Dental Research, vol. 88, (IADR Abstracts): abstract no. 2854, 2009.

[24] A. S. Paula, K. K. Mahesh, C. M. L. dos Santos, J. P. H. G. Canejo, and F. M. B. Fernandes, "One- and two-step phase transformation in Ti-rich NiTi shape memory alloy," International Journal of Applied Electromagnetics and Mechanics, vol. 23, no. 1-2, pp. 25-32, 2006.

[25] A. S. Paula, K. K. Mahesh, and F. M. Braz Fernandes, "Evolution of phase transformations after multiple steps of marforming in Ti-rich Ni-Ti SMA," The European Physical Journal, vol. 158, no. 1, pp. 45-51, 2008.

[26] A. S. Paula, K. K. Mahesh, C. M. L. dos Santos, F. M. Braz Fernandes, and C. S. da Costa Viana, "Thermomechanical behavior of Ti-rich NiTi shape memory alloys," Materials Science and Engineering A, vol. 481-482, no. 1-2, pp. 146-150, 2008.

[27] A. Nagasawa, "A new phase transformation in the NiTi alloy," Journal of the Physical Society of Japan, vol. 29, no. 5, p. 1386, 1970.

[28] H. C. Ling and R. Kaplow, "Macroscopic length changes during the $\mathrm{B} 2 \leftrightarrows \mathrm{R}$ and $\mathrm{M} \rightarrow \mathrm{B} 2$ transitions in equiatomic NiTi alloys," Materials Science and Engineering, vol. 51, no. 2, pp. 193-201, 1981.

[29] G. Gambarini, R. Gerosa, M. de Luca, M. Garala, and L. Testarelli, "Mechanical properties of a new and improved nickel-titanium alloy for endodontic use: an evaluation of file flexibility," Oral Surgery, Oral Medicine, Oral Pathology, Oral Radiology and Endodontology, vol. 105, no. 6, pp. 798-800, 2008.

[30] S. B. Alapati, W. A. Brantley, M. Iijima et al., "Metallurgical characterization of a new nickel-titanium wire for rotary endodontic instruments," Journal of Endodontics, vol. 35, no. 11, pp. 15891593, 2009.

[31] M. Iijima, W. A. Brantley, W. H. Guo, W. A. T. Clark, T. Yuasa, and I. Mizoguchi, "X-ray diffraction study of low-temperature phase transformations in nickel-titanium orthodontic wires," Dental Materials, vol. 24, no. 11, pp. 1454-1460, 2008.

[32] S. B. Alapati, W. A. Brantley, M. Iijima et al., "Micro-XRD and temperature-modulated DSC investigation of nickel-titanium rotary endodontic instruments," Dental Materials, vol. 25, no. 10, pp. 1221-1229, 2009.

[33] S. Vilaverde-Correia, Estudo do comportamento em serviço de limas endodônticas superelásticas de Ni-Ti [Ph.D. thesis], Dental
Medicine Faculty, University of Lisbon, Lisbon, Portugal, 2009 (Portuguese).

[34] J. Liu, Characterization of new rotary endodontic instruments fabricated from special thermomechanically processed $\mathrm{Ni}$-Ti wire [Ph.D. thesis], Ohio State University, Columbus, Ohio, USA, 2009.

[35] "ANSYS 11 elements reference manual," 2007.

[36] D. C. Lagoudas, Shape Memory Alloys: Modeling and Engineering Applications, Springer Science+Business Media, LLC, New York, NY, USA, 2008. 

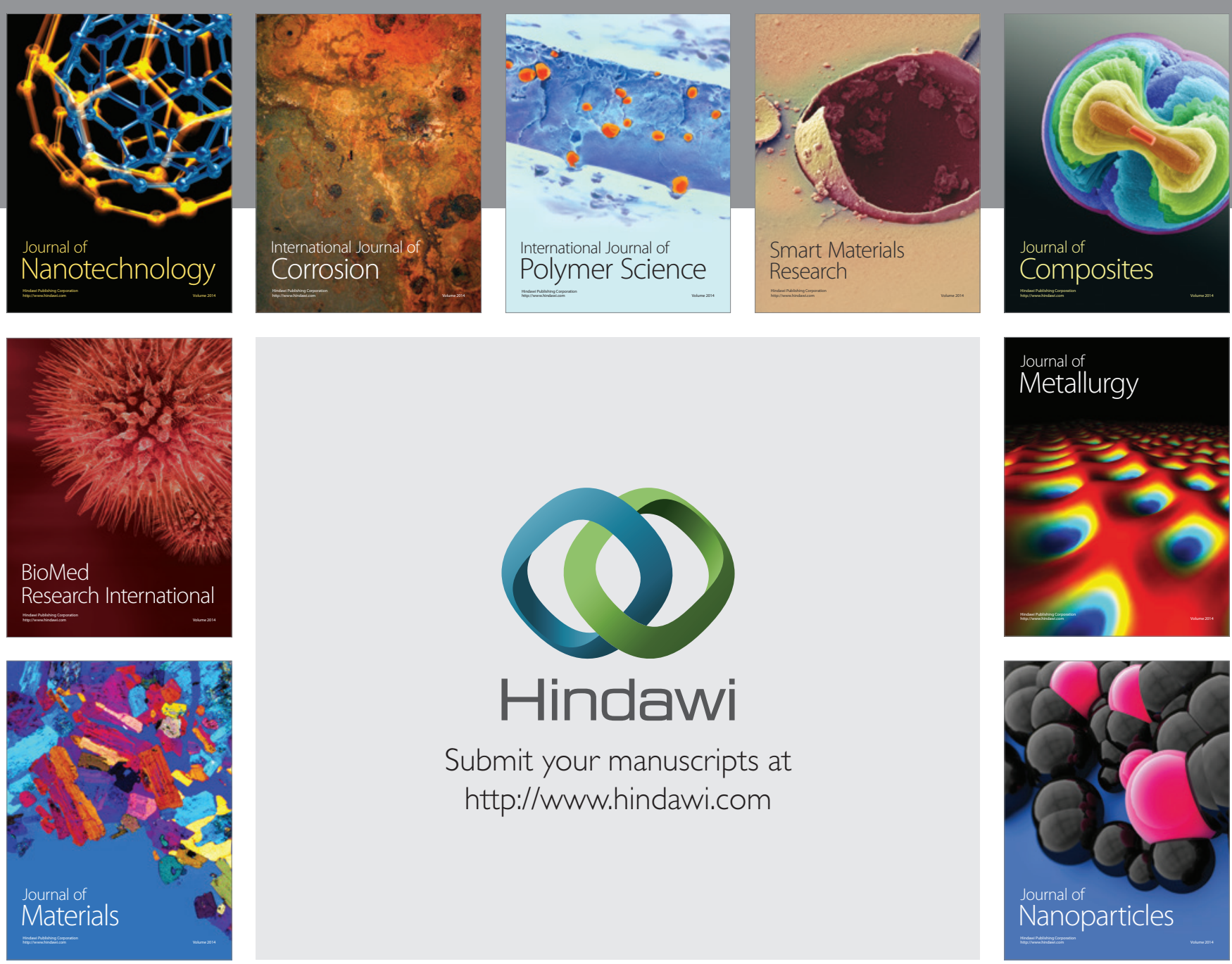

Submit your manuscripts at http://www.hindawi.com
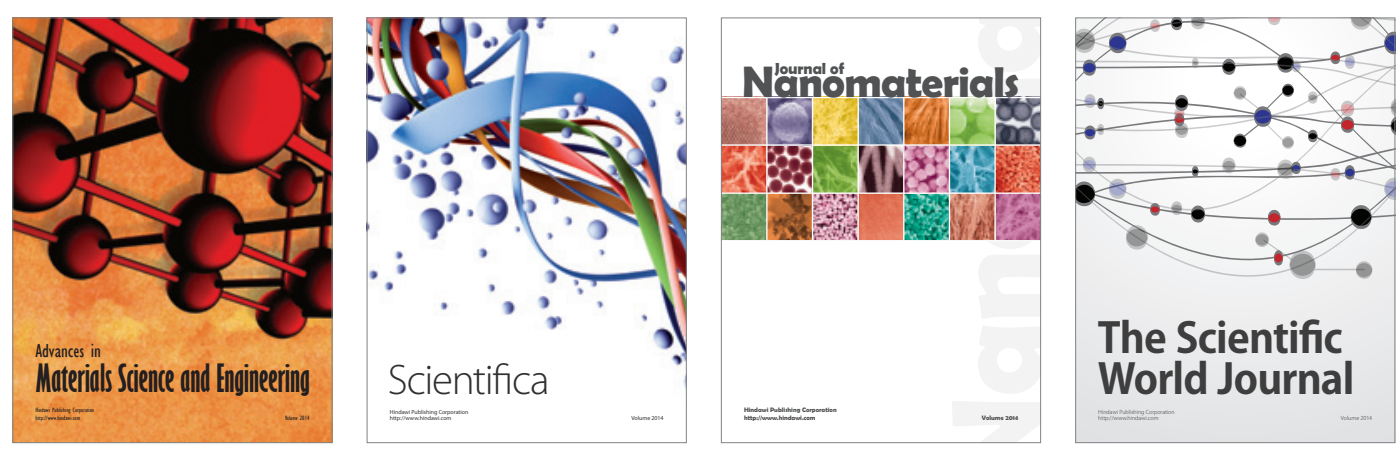

\section{The Scientific World Journal}
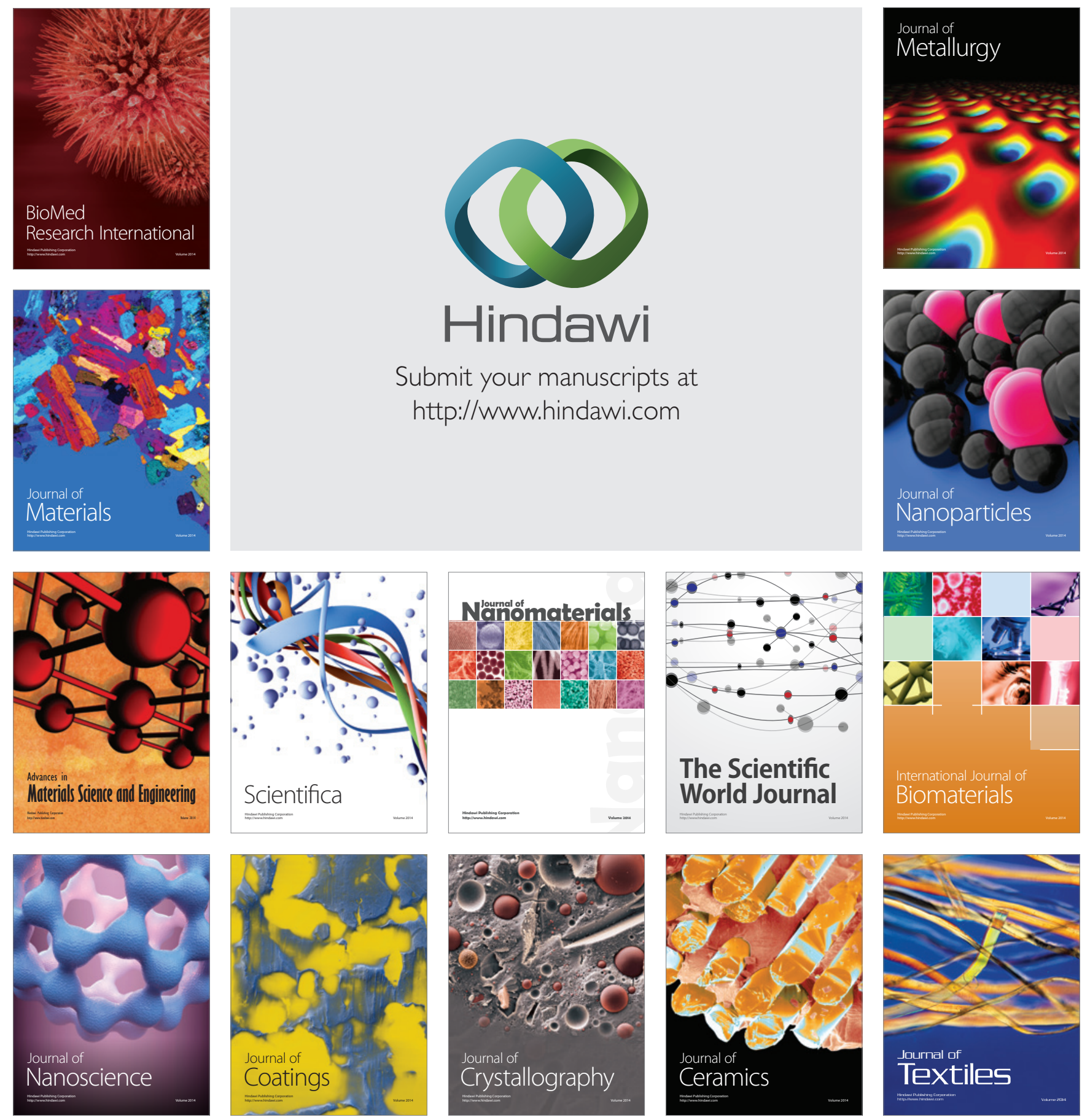